\title{
Protection from Viral Infections by Human Milk Oligosaccharides: Direct Blockade and Indirect Modulation of Intestinal Ecology and Immune Reactions
}

\author{
Betsy Yang ${ }^{1}$, Hau Chuang ${ }^{2}$ and Rong-Fu Chen*,3 \\ ${ }^{1}$ Biology Class of 2014, University of North Carolina, Chapel Hill, NC27599, USA \\ ${ }^{2}$ Department of Medical Research, Kaohsiung Chang Gung Memorial Hospital, Kaohsiung 833, Taiwan; \\ ${ }^{3}$ Department of Medical Research, Show Chwan Memorial Hospital in Chang Bing, Lu-gang, Changhua 505, Taiwan
}

\begin{abstract}
Sugar-lectin interactions play an important role in viral infections. Many viruses, such as human immunodeficiency virus (HIV), Ebola, dengue, cytomegalovirus, and hepatitis C, possess glycans that recognize C-type lectins, especially CD209 (DC-SIGN), for infection. Other viruses possess lectins on their surfaces that recognize glycan epitopes on human epithelial cells for infection. Human and avian influenza viruses recognize different glycan epitopes, sialic acid$\alpha 2,6$ galactose (SA- $\alpha 2,6 \mathrm{Gal}$ ) and SA- $\alpha 2,3 \mathrm{Gal}$, respectively, as their receptors, resulting in different host ranges for these two viruses. We and others have shown that sialogalactosides and fucosyllactoses are receptors for enterovirus 71 and norovirus infections, respectively; human milk oligosaccharides (HMOs) could block enterovirus 71 and norovirus infections. Several lines of evidence also suggest that HMOs cannot only mimic viral receptors and block viral infections, but also raise immune responses through sugar/lectin (galactosides/galactins and sialylglycans/Siglecs) interactions and improve gut ecology by nurturing intestinal cells and/or intestinal microbiota. This review article summarizes how and why HMOs directly or indirectly protect humans from viral infections.
\end{abstract}

Keywords: Fucosyltransferase, Lactose, Galactose, Glycosyltransferase, Glycan, Human milk oligosaccharides (HMOs), Lectin, Lewis X, Sialic acid, Viral infection.

\section{VIRAL INFECTIONS MEDIATED BY SUGAR- LECTIN INTERACTIONS}

Microorganisms possess pathogen-associated molecular patterns (PAMPs) to recognize hosts during infection; human hosts have pattern recognition receptors (PRRs) to detect pathogens for immune responses and defense [1]. The interactions between PAMPs and PRRs include the sugarlectin interactions that play an important role in the infection of human cells by viruses [2, 3]. Many viruses possess glycan epitopes on their surfaces that recognize receptors (lectins) on human cells. It is well known that human immunodeficiency virus (HIV) possesses glycans (high mannose type) on gp120 that bind dendritic-cell-specific ICAM-3grabbing non-integrin (DC-SIGN, also called CD209) during infection of human leukocytes [3]. Viruses such as Ebola, dengue, cytomegalovirus, and hepatitis $\mathrm{C}$ also possess surface glycans that recognize DC-SIGN or other C-type lectins during infection [3-6] (Table 1). In contrast, other viruses possess surface lectins that recognize glycans on human epithelial cells. Human and avian influenza viruses recognize different glycan epitopes, sialic acid- $\alpha 2,6$ galactose (SA$\alpha 2,6 \mathrm{Gal})$ and SA- $\alpha 2,3 \mathrm{Gal}$, respectively, as their receptors,

\footnotetext{
*Address correspondence to this author at the No. 6-1 Lu-Kung Road, Chang Bing Coastal Industrial Park Lu-gang, Changhua 505, Taiwan;

Tel: +886-4-7813888; Fax: +886-4-7073226; E-mail: den2.th1@gmail.com
}

resulting in different host ranges for these two viruses [7]. Coxsackievirus A24 recognizes SA- $\alpha 2,3 \mathrm{Gal}$ on intestinal cells as a receptor [8]; we and others have shown that sialogalactosides [9] and sialomucin (CD162) [10] are receptors for enterovirus 71 infection of intestinal cells. Both SA$\alpha 2,6 \mathrm{Gal}$ and SA- $\alpha 2,3 \mathrm{Gal}$ from human milk oligosaccharides (HMOs) have been shown to block enterovirus 71 infection of DLD-1 intestinal cells [9]. Moreover, norovirus and rotavirus recognize blood group carbohydrates and sialylglycoproteins, respectively, as receptors. Human milk containing secretary blood group carbohydrates such as fucosylated Lewis antigens and sialylgoycoproteins such as lactoadherin have been shown to prevent infection by these viruses [11, 12]. Differential expression of cell surface glycans or lectins and exogenous intake of soluble oligosaccharides from human milk may block or prevent viral infections.

\section{HMOS CONTAIN POLYLACTOSYL OLIGOSAC- CHARIDES CAPABLE OF NURTURING MICROBI- OTA IN THE INFANT GUT}

It is well known that infants who are breastfed have fewer respiratory and gastrointestinal infections than those who are fed cow's milk infant formula $[12,13]$. The composition and diversity of oligosaccharides in human milk, particularly in colostrum, are very different from those of cow's milk [14-16]. The protective effects of human milk can be 
Table 1. Patterns of Viral Infection by Sugar-lectin Recognition

\begin{tabular}{|c|c|c|c|}
\hline Patterns & Virus (Epitopes) & Host (Receptors) & References \\
\hline \multicolumn{4}{|c|}{ Glycans recognize lectins: } \\
\hline & Ebola (surface glycoprotein) & Human (CD209), LSECtin & {$[4,5]$} \\
\hline & Dengue (Glycan on E antigen) & Human (CD209, CD299) & [6] \\
\hline & Influenza (Hemagglutinin, H1) & Human (SA- $\alpha 2,6 \mathrm{Gal})$ & [7] \\
\hline & Avian Flu (Hemagglutinin, H5) & Human (SA- $\alpha 2,3 \mathrm{Gal})$ & [7] \\
\hline & Coxsackievirus 24 & Human (SA- $\alpha 2,3 \mathrm{Gal})$ & {$[8]$} \\
\hline & Enterovirus 71 & Human (sialylglycans) & {$[9,10]$} \\
\hline
\end{tabular}

attributed to HMOs rather than secretory $\operatorname{IgA}$ because cow's milk has IgA concentrations similar to that of human milk but 20 -fold lower concentrations of oligosaccharides [14, $15]$.

HMOs are made of lactose (galactose + glucose), fucose, $\mathrm{N}$-acetylglucosamine and $\mathrm{N}$-acetylneuramic acid (sialic acid). Mass spectrometric analysis indicates that HMOs are composed of 2 to 32 oligosaccharides, of which the number of galactose or fucose residues can be up to 15 . There is great diversity in the structural isomers seen in HMOs, estimated to include many thousands of oligosaccharides [15]; at present, 115 HMOs have been characterized [16]. Most HMOs are indigestible in the human gastrointestinal tract. However, it is generally accepted that HMOs can be digested by certain bacteria in the gut and are beneficial to the selection of microbiota that promotes better gut ecology. HMOs promote the growth of normal flora such as Lactobacillus and Bifidobacterium species in the infant gut $[14,17]$. LoCascio et al. [18] have recently reported that Bifidobacterium longum in the infant gut preferentially utilizes short-chain over complex HMOs and is associated with the expression of glycosidases capable of degrading oligosaccharides. These results suggest that the prebiotic effects of HMOs are structure-specific and may vary depending on individual differences in maternal lactation and microbiota of the infant gut [13-19].

\section{STRUCTURES OF HMOS}

HMOs containing the lacto- $N$-biose core unit (LNB; Gal $\beta 1-3$ GlcNAc) are called 'type 1' structures; those with a lactosamine (Gal $\beta 1-4 \mathrm{GlcNAc}$ ) core unit are called 'type 2' structures as shown in Fig. (1). Oligosaccharides in human milk are predominantly type 1 structures $[16,20]$. Both LNB and lactosamine core units are repeatedly elongated from a $\beta 1-3$ or $\beta$ 1-4 para linkage to the terminal lactose (Gal $\beta 1$ 4Glc) [20]. More complex oligosaccharides contain additional $\beta$ 1-6 linkages in branched forms and side chain fucosylation via $\alpha 1-2 / 3 / 4$ linkages and/or sialylation via $\alpha 2-3 / 6$ linkages. Thus, HMOs containing poly-lacto-N-biose or poly-acetyllactosamine with fucosylated and/or sialylated compounds can be composed of hundreds to thousands of oligosaccharides. These compounds, with or without branched adducts, are usually stable and indigestible by human intestinal cells.

HMOs may serve as natural barriers for the prevention of microbial adhesion to cells and infection. Some HMOs have been shown to modulate epithelial glycosyltransferase expression, possibly regulating the surface glycan profiles that affect the susceptibility of human cells to viral infection [2123]. One study found that the sialic acid in human milk was mostly bound to free oligosaccharides, while most of the sialic acid in infant formulas derived from cow's milk was bound to glycoproteins [24].

\section{HMOS ARE SECRETARY CARBOHYDRATES, CA- PABLE OF INTERFERING WITH MICROBIAL AD- HESION TO HOST CELLS}

HMOs are secreted into breast milk by mammary glands. Approximately $90 \%$ of the HMOs in human breast milk are found undigested in infants' feces [17-23]. This suggests that HMOs play other roles beyond their prebiotic effects on microbiota ecology [21]. In fact, there is evidence that HMOs stimulate epithelial cells and afford protection from infections by raising innate immunity and/or nurturing gut ecology [21, 22]. HMOs contain heterogeneously soluble glycans that are present in high concentrations (up to $12 \mathrm{~g} / \mathrm{l}$ ) in human milk, particularly in colostrum. Milk from animals such as cows and goats also contains oligosaccharides but generally 10 -fold lower in concentration and less diverse in composition [16]. Varying amounts and compositions of oligosaccharides are found in different mothers in different stages of breast feeding. Structures and quantities of HMOs vary between maternal genotypes, particularly with respect to the content of fucosylated oligosaccharides, which determines whether HMOs are secreted or not. 
Core units

Linear extensions

Poly-lacto-N-biose (LNB)

(Galß1,3GlcNAc-lactose)

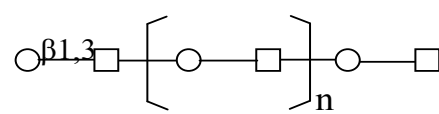

Complex structures

Branched

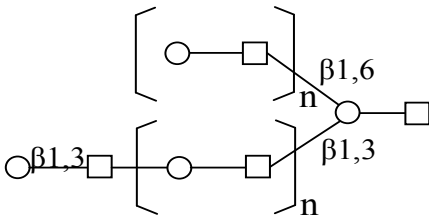

Fucosylated
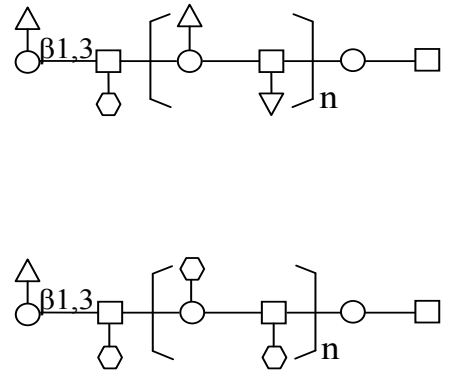

Sialylated
Type 2 structure

Poly-lactosamine

(Galß1,4GlcNAc-lactose)
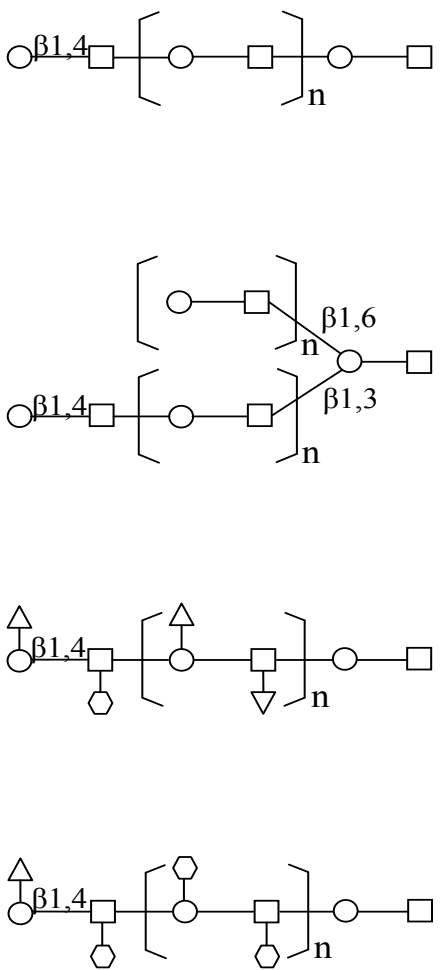

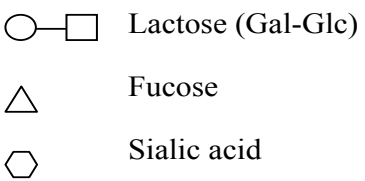

The $\triangle$ or $\square$ position is changeable depending on glycotransferases, and 'n'

indicates the range of biose repeats from 0 to 14 .

Fig. (1). HMO structures.

\section{BLOOD GROUP CARBOHYDRATES IN HMOS PROTECT INFANTS FROM INFECTIONS}

The blood group types $\mathrm{A}, \mathrm{B}, \mathrm{O}$, and Lewis are determined by carbohydrate compositions. The $\mathrm{H}$ antigen is a tetraose carbohydrate consisting of galactose, Nacetylglucosamine, galactose, and fucose attached to a membrane protein or ceramide on human cells, including red blood cells. The blood group A antigen results from a glycosyltransferase that adds $\mathrm{N}$-acetylgalactosamine to the galactose end of the $\mathrm{H}$ antigen. The blood group $\mathrm{B}$ antigen results from another glycosyltransferase that adds galactose to the galactose end of the $\mathrm{H}$ antigen. Blood group $\mathrm{O}$ arises from an exon 6 deletion that eliminates glycosyltransferase activity, resulting in the expression of $\mathrm{H}$ antigen only, with no A or B antigen expression [25]. Lewis antigens are made of trioses or tetroses determined by the activity of fucosyltransferases (FUT2, FUT3 and FUT4). FUT2 converts the Lewis a antigen (Le ${ }^{\mathrm{a}}$, Gal-GlcNAc-Fuc) to Lewis $b$ antigen (Le ${ }^{b}$, Fuc-Gal-GlcNAc-Fuc) by transferring fucose to the galactose end of Le antigen $[25,26]$. This is the same fucosyltransferase (FUT2) that converts membranebound blood group $\mathrm{A}, \mathrm{B}$, and $\mathrm{H}$ antigens into soluble forms by transferring a fucose residue to the galactose end of the $\mathrm{H}$ antigen, allowing humans to secrete blood group antigens into body fluids, including human milk. Most humans $(80 \%)$ carry the FUT2 gene and are thus capable of secreting blood group antigen; these individuals are referred to as 'secretors' (SeSe/Sese); the remaining $20 \%$, called 'non-secretors' (sese), lack FUT2 expression and thus do not secrete blood group antigens. HMOs from nonsecretors' milk possess no $\alpha$-2-fucosylgalactosides, but do contain other $\alpha$-3-fucosyl 
Table 2. HMO Functions and Mechanisms of Protection from Infections

\begin{tabular}{|c|c|c|c|}
\hline Protective Mechanism & HMO Components & Function & References \\
\hline \multicolumn{4}{|l|}{ Anti-microbial effects: } \\
\hline 1. Prebiotics & Lactose, poly-lactosamine poly-lacto-N-biose etc. & Prevent bacterial infections after viral infections & [14-23] \\
\hline \multirow[t]{3}{*}{ 2. Receptor Competition } & $\begin{array}{l}\text { Secretor HMOs: } \\
\text {-- secretory } \mathrm{A}, \mathrm{B}, \mathrm{H} \text {, and Lewis b }\left(\mathrm{Le}^{\mathrm{b}}\right) \text { antigens }\end{array}$ & $\begin{array}{l}\text { Compete with viral receptors to block viral infec- } \\
\text { tions }\end{array}$ & [29-32] \\
\hline & $\begin{array}{l}\text { Other fucosylated HMOs: } \\
\text {-- } \mathrm{Le}^{\mathrm{y}}, \mathrm{Le}^{\mathrm{x}} \text {, and } \mathrm{sLe}^{\mathrm{x}} \text {, etc. }\end{array}$ & & \\
\hline & $\begin{array}{l}\text { Other sialylated HMOs: } \\
\text { SA } \alpha 2,3 \text { galactose } \\
\text { SA } \alpha 2,6 \text { galactose }\end{array}$ & & \\
\hline \multicolumn{4}{|l|}{ Cell interactions: } \\
\hline 3. Cell-cell Interaction & Sialyllactoses in colostrums & Nurture infant gut and brain cells & {$[42-46]$} \\
\hline \multirow[t]{2}{*}{ 4. Immune Regulation } & Fucosyl HMOs & $\begin{array}{l}\text { Bind or compete selectins to induce anti- } \\
\text { inflammation }\end{array}$ & [47-49] \\
\hline & Galactosyl or sialyl HMOs & $\begin{array}{l}\text { Bind or compete galectins or Siglecs mediated } \\
\text { immune responses }\end{array}$ & {$[50-52]$} \\
\hline
\end{tabular}

galactosides or $\alpha$-4-fucosyl $\mathrm{N}$-acetylglucosamine residues. Thus, individuals carrying the $\mathrm{Le}^{\mathrm{a}}$ antigen will not secrete the $\mathrm{A}, \mathrm{B}$ or $\mathrm{H}$ antigens (ABH non-secretors); the $\mathrm{Le}^{\mathrm{b}}$ antigen is only found in secretors [25]. Mothers with different blood group types have different HMO profiles because HMOs have the same glycan structures found in mucosal and epithelial secretions [22, 24-27].

The concentrations and compositions of HMOs are different between human colostrum and mature human milk. The total HMOs are much higher in colostrum than those in mature human milk (22-24 g/l vs. 12-13 g/l), and the concentrations of 2-fucosyllactose and 3-sialyllactose were significantly higher in colostrum [16]. The facts that colostrum has significantly higher concentrations of fucosyllactose and sialyllactose residues and colostrum is known to be important for the protection of infants against certain infections $[27,28]$, suggest that sialyl and fucosyl HMOs are required for the protection in human infants from infections during early lactation [20,24]. HMOs with fucosylated and/or sialylated residues might block the binding and infection of bacteria and viruses to epithelial cells $[29,30]$. For instance, the blood H2-type antigen (Fuc $\alpha 1,2 \mathrm{Gal} \beta 1,4 \mathrm{GlcNAc}$ ) is a receptor for norovirus infection, and soluble $\mathrm{H} 2$ oligosaccharides in milk can prevent norovirus infection [29, 31]. Moreover, individuals with an $\mathrm{O}$ blood group were found to be more susceptible to norovirus infection than those with a B blood group [32]. Polylactosyl oligosaccharides (with or without fucosylated or sialylated residues) can also mimic viral receptors and thus inhibit viral infections [29-32]. These glycans function as competitors for receptors and may prevent infection by inhibiting pathogen binding to host epithelial cells. Such glycans are usually stable at room temperature and are intrinsically sweet tasting [33,34]. These features may allow them to be economically distributed as a drink for use by the general population; glycan supplements would be particularly beneficial to infants, who are more susceptible to infections.

\section{FUNCTIONS AND MECHANISMS OF HMOS ON THE PROTECTION FROM VIRAL INFECTIONS}

Protection of infant infections and mortality by human milk has been historically attributed to its nutritional suitability for infants, IgA antibody content, and its lactoseenriched prebiotic effects [13-19]. Many recent studies have found the benefits of human milk to go beyond what can be attributed to nutrient content or prebiotic effects. Table 2 summarizes the 4 major functions of HMOs; the first 2 functions are related to anti-microbial effects and the other 2 functions are related to immune modulation through host cell interactions.

\section{HMOs Act as Prebiotics}

Human milk is enriched in lactose, polyacetyllactosamine and poly-lacto-N-biose, which are indigestible by humans but nurture Lactobacillus and Bifidobacillus species in the gut. These normal flora metabolize lactose and HMOs containing polylactosamine and poly-lacto-N-biose. The metabolites from lactose, polylactosamine, and poly-lacto-N-biose favor the growth of normal flora but inhibit other pathogens by causing acidic conditions, resulting in better microbiota ecology [13-19]. The better microbiota ecology may, therefore, protect from offensive bacterial infections after viral infections.

\section{Soluble HMOs Compete with Pathogen Adhesion and Infection}

Oligosaccharides are usually soluble but are not necessarily secreted. HMOs are soluble glycans secreted by mammary glands. The secretory pathways of HMOs are not 
completely understood, but are presumably similar to those of mucosal glands in the gastrointestinal, respiratory, and urogenital tracts. HMOs become secretory through the transfer of fucose to a galactose or glucosamine residue at the $\alpha 2$ position by fucosyltranferase 2 (FUT2) as described above. Most oligosaccharides in human milk are $\alpha 2$ fucosylated and relatively protective from viral infections [35], and those without FUT2 called non-secretors are usually more susceptible to the infection by viruses that recognize fucosyl oligosaccharides as receptors [36]. In addition to FUT2, other fucosyltransferases (FUT3, FUT5, and FUT6) and sialyltransferases (e.g. ST6Gal) can affect the glycan profiles of human cells, thereby influencing susceptibility to infections by viruses whose entry is mediated by sialyl or fucosyl oligosaccharides [37,38]. For instance, addition of fucose to the $\alpha 3$ position by FUT3 converts type 2 core antigen (Gal $\beta 1,4 \mathrm{GlcNAc}$ ) to Lewis $\mathrm{X}$ antigen ( $\mathrm{Le}^{\mathrm{x}}$; Gal $\beta 1,4$ GlcNAc $\alpha 1,3$ Fuc) and converts blood $\mathrm{H} 2$ antigen (Fuc $\alpha 1,2$ Gal $\beta 1,4$ GlcNAc) to Lewis Y antigen (Le ${ }^{\mathrm{y}}$; Fuc $\alpha 1,2$ Gal $\beta 1,4$ GlcNAc $\alpha 1,3$ Fuc) [39]. Lewis X components in human milk are able to bind to DCSIGN and thereby prevent the capture and subsequent transfer of HIV-1 to CD4+ T lymphocytes [40]. Le ${ }^{\mathrm{x}}$ and $\mathrm{Le}^{\mathrm{y}}$ can be sialylated by sialyltransferases at position $\alpha 2,3$ or $\alpha 2,6$, producing sialyl $\mathrm{Le}^{\mathrm{x}}$ and sialyl $\mathrm{Le}^{\mathrm{y}}$. $\mathrm{sLe}^{\mathrm{x}}$ has been shown to be the common receptor recognized by $\mathrm{H} 5, \mathrm{H} 6, \mathrm{H} 7$, and $\mathrm{H} 9$ avian influenza viruses [41]; $\mathrm{sLe}^{\mathrm{x}}$ in milk may therefore be able to inhibit avian influenza virus infections.

\section{HMOs May Nurture Intestinal Cell Differentiation}

Sialyl oligosaccharides in human milk are more prominent in colostrum [27, 42], which may benefit premature babies by decreasing the incidence of inflammatory bowel diseases via its anti-inflammatory effects [43]. Furthermore, sialyl HMOs are high in human milk but much lower in infant formulas. Experimental studies show that a diet rich in sialic acid increases the brain sialic acid levels in infant animals, enhances expression of two learning-related genes, and promotes learning and memory [44]. Since most of HMOs $(>90 \%)$ are ingestible in gastrointestinal tract, the concentration of HMOs in blood or brain may be too low to directly affect brain development. Thus, sialyl HMOs may directly nurture growth and development of the gastroin-testinal tract that indirectly influence immunity and the brain development of infants. In support of this concept, recent studies demonstrated that HMOs mediate growth signals in intestinal cells through mechanisms other than the epidermal growth factor pathway $[45,46]$. Whether the HMOs modulation of intestinal cell differentiation is associated with susceptibility of viral infections remains to be determined.

\section{HMOs Act as Ligands for Innate Immune Responses}

Recent evidence has shown that HMOs mediate signal cascades in immune and other types of cells. Fucosylated and sialylated oligosaccharides can bind to selectins (Pselectin and E-selectin) on platelets and endothelial cells. Selectins expressed on activated endothelial cells bind to fucose-containing Lewis antigens such as $\operatorname{sLe}^{\mathrm{x}}$ on leukocytes, which leads to leukocyte rolling. The leukocytes subsequently transmigrate into subendothelial regions and extravasate [47]. HMOs resemble secretory Lewis antigens and may compete for selectin binding, resulting in antiinflammatory effects $[48,49]$. The backbone of HMOs is formed by poly- $N$-acetyllactosamines, which can bind galactoside-binding lectins (galectins). Galectins are a family of lectins that bind beta-galactosides. At least 12 different galectins have been identified with a variety of functions including regulation of cell growth, proliferation, and apoptosis, as well as immune functions [50]. Expression and interactions of galactosides and galectins may affect gut ecology and leukocyte function that may influence anti-viral defense. Different poly-lactosyl oligosaccharides in HMOs have varied affinities to different galectins, resulting in different immune regulation [51]. Many HMOs also contain sialic acid ( $\alpha 2-3$ and/or $\alpha 2-6)$ bound to galactose or glucosamine. Sialic acid-containing oligosaccharides have been shown to bind receptors called sialic acid binding immunoglobulin-like lectins (Siglecs). There are at least 12 Siglecs that have been identified. Most of them have two conserved ITIM-like motifs (immunoreceptor tyrosine-based inhibitory motifs) in their cytoplasmic tails, suggesting their involvement in cellular activation or inactivation [52]. HMOs with sialic acid side chains, which may recognize certain Siglecs on intestinal cells and leukocytes, have been proposed to mediate immunoregulatory functions [20, 21].

In summary, HMOs possess antiviral activity that is related to a direct blockade of viral infection or indirect modulation of intestinal ecology and immune responses. In addition to HMOs, glycoproteins in milk such as transferrin which has been shown to have potent activities against hepatitis B virus, human immunodeficiency virus and human cytomegalovirus replication [53,54]. Another mucin glycoprotein with molecular weight of $46-\mathrm{kD}$ in human milk has also been shown to mediate antiviral activity directed against rotavirus [55]. Dietary supplements with HMOs or milk glycoproteins might be suitable for the prevention of infections in infants because of their stability and sweet taste [33, 34]. Further studies on the protective mechanisms of HMOs against viral infections by modulating cell surface expression of sugar epitopes or lectins, or by additional intake of exogenous HMOs might provide better strategies for prevention of viral infections.

\section{REFERENCES}

[1] Kumar H, Kawai T, Akira S. Pathogen recognition by the innate immune system. Int Rev Immunol 2011; 30: 16-34.

[2] Rogers KM, Heise M. Modulation of cellular tropism and innate antiviral response by viral glycans. J Innate Immun 2009; 1: 40512.

[3] Geijtenbeek TB, van Kooyk Y. Pathogens target DC-SIGN to influence their fate DC-SIGN functions as a pathogen receptor with broad specificity. APMIS 2003; 111: 698-714.

[4] Gardner JP, Durso RJ, Arrigale RR et al. L-SIGN (CD 209L) is a liver-specific capture receptor for hepatitis $\mathrm{C}$ virus. Proc Natl Acad Sci USA 2003; 100: 4498-503.

[5] Powlesland AS, Fisch T, Taylor ME, Smith DF, Tissot B, Dell A. Pöhlmann S, Drickamer K. A novel mechanism for LSECtin binding to Ebola virus surface glycoprotein through truncated glycans. $\mathrm{J}$ Biol Chem 2008; 2831: 593-602.

[6] Wang L, Chen RF, Liu JW, et al. DC-SIGN (CD209) Promoter $336 \mathrm{~A} / \mathrm{G}$ polymorphism is associated with dengue hemorrhagic fever and correlated to DC-SIGN expression and immune augmentation. PLoS Negl Trop Dis 2011; 5:e 934. 
[7] Suzuki Y. The highly pathogenic avian influenza H5N1-initial molecular signals for the next influenza pandemic. Chang Gung Med J 2009; 32: 258-63.

[8] Nilsson EC, Jamshidi F, Johansson SM, Oberste MS, Arnberg N. Sialic acid is a cellular receptor for coxsackievirus A24 variant, an emerging virus with pandemic potential. J Virol 2008; 82: 3061-8.

[9] Yang B, Chuang H, Yang KD. Sialylated glycans as receptor and inhibitor of enterovirus 71 infection to DLD-1 intestinal cells. Virol J 2009; 6: 141.

[10] Nishimura Y, Shimojima M, Tano Y, Miyamura T, Wakita T, Shimizu H. Human P-selectin glycoprotein ligand-1 is a functional receptor for enterovirus 71. Nat Med 2009; 15: 794-7.

[11] Jiang X, Huang P, Zhong W, et al. Human milk contains elements that block binding of noroviruses to human histo-blood group antigens in saliva. J Infect Dis 2004; 190: 1850-9.

[12] Morrow AL, Ruiz-Palacios GM, Altaye M, et al. Human milk oligosaccharides are associated with protection against diarrhea in breast-fed infants. J Pediatr 2004; 145:297-303.

[13] Sazawal S, Dhingra U, Hiremath G, et al. Prebiotic and probiotic fortified milk in prevention of morbidities among children: community-based, randomized, double-blind, controlled trial. PLoS One 2010; 5: e12164.

[14] Rockova S, Rada V, Marsik P, et al. Growth of bifidobacteria and clostridia on human and cow milk saccharides. Anaerobe 2011; 17: 223-5.

[15] Newburg DS. Neonatal protection by an innate immune system of human milk consisting of oligosaccharides and glycans. J Anim Sci 2009; 87(13 Suppl ): 26-34.

[16] Urashima T, Kitaoka M, Asakuma S, Messer M. Milk oligosaccharides. Adv Dairy Chem 2009; 3: 295-349.

[17] German JB, Freeman SL, Lebrilla CB, Mills DA. Human milk oligosaccharides: evolution, structures and bioselectivity as substrates for intestinal bacteria. Nestle Nutr Workshop Ser Pediatr Program 2008; 62: 205-18.

[18] LoCascio RG, Ninonuevo MR, Freeman SL, et al. Glycoprofiling of bifidobacterial consumption of human milk oligosaccharides demonstrates strain specific, preferential consumption of small chain glycans secreted in early human lactation. J Agric Food Chem 2007; 55: 8914-9.

[19] Sela DA, Mills DA. Nursing our microbiota: molecular linkages between bifidobacteria and milk oligosaccharides. Trends Microbiol 2010; 18: 298-307.

[20] Bode L. Recent advances on structure, metabolism, and function of human milk oligosaccharides. J Nutr 2006; 136: 2127-30.

[21] Bode L. Human milk oligosaccharides: prebiotics and beyond. Nutr Rev 2009; 67: S183-S191.

[22] de Kivit S, Kraneveld AD, Garssen J, Willemsen LE. Glycan recognition at the interface of the intestinal immune system: Target for immune modulation via dietary components. Eur J Pharmacol 2011; 668 (Suppl. 1): S124-32.

[23] Sela DA. Bifidobacterial utilization of human milk oligosaccharides. Int J Food Microbiol 2011; 149: 58-64.

[24] Wang B, Brand-Miller J, McVeagh P, Petocz P. Concentration and distribution of sialic acid in human milk and infant formulas. Am $\mathbf{J}$ Clin Nutr 2001;74: 510-15.

[25] Oriol R, Le Pendu J, Mollicone R. Genetics of ABO, H, Lewis, X and related antigens. Vox Sang 1986; 51: 161-71.

[26] Lewis antigen system. Retrieved from Wikipedia, the free encyclopedia http://en.wikipedia.org/wiki/Lewis antigen system

[27] Asakuma S, Urashima T, Akahori M, et al. $\bar{V}$ ariation of major neutral oligosaccharides levels in human colostrum. Eur J Clin Nutr 2008; 62: 488-94

[28] Huffman SL, Zehner ER, Victora C. Can improvements in breastfeeding practices reduce neonatal mortality in developing countries? Midwifery 2001; 17: 80-92.

[29] Morrow AL, Ruiz-Palacios GM, Jiang X, Newburg DS. Humanmilk glycans that inhibit pathogen binding protect breast-feeding infants against infectious diarrhea. J Nutr 2005; 135:1304-7.

[30] Ruiz-Palacios GM, Cervantes LE, Ramos P, Chavez-Munguia B, Newburg DS. Campylobacter jejuni binds intestinal $\mathrm{H}(\mathrm{O})$ antigen (Fuc alpha 1, 2Gal beta 1, 4GlcNAc), and fucosyloligosaccharides of human milk inhibit its binding and infection. J Biol Chem 2003; 278: 14112-20.

[31] Hutson AM, Atmar RL, Graham DY, Estes MK. Norwalk virus infection and disease is associated with $\mathrm{ABO}$ histo-blood group type. J Infect Dis 2002;185: 1335-7.
[32] Le Pendu J. Histo-blood group antigen and human milk oligosaccharides: genetic polymorphism and risk of infectious diseases. Adv Exp Med Biol 2004; 554: 135-43.

[33] Carbohydrates In Food Chemistry, Hans-Dieter Belitz,Werner Grosch, Peter Schieberle. $3^{\text {rd }}$ ed, Springer-Verlag Berlin Heidelburg, 2004; pp. 245-341.

[34] Foda MI, Kholif SM, Kholif AM. Evaluation of goat milk containing galactooligosaccharides after supplementing the ration with amino acids. Intl J Dairy Sci 2009; 4: 27-33.

[35] Newburg DS, Ruiz-Palacios GM, Morrow AL. Human milk glycans protect infants against enteric pathogens. Annu Rev Nutr 2005; 25: 37-58

[36] Stahl BS, Thurl S, Henker TJ, Siegel M, Finke B, Sawatzki G. Detection of four human milk groups with respect to Lewis-bloodgroup-dependent oligosaccharides by serologic and chromatographic analysis. Adv Exp Med Biol 2001; 501: 299-306.

[37] Nordén R, Nyström K, Olofsson S. Activation of host antiviral RNA-sensing factors necessary for herpes simplex virus type 1activated transcription of host cell fucosyltransferase genes FUT3, FUT5, and FUT6 and subsequent expression of sLe(x) in virusinfected cells. Glycobiology 2009; 19: 776-88.

[38] Kitazume S, Oka R, Ogawa K, et al. Molecular insights into betagalactoside alpha2,6-sialyltransferase secretion in vivo. Glycobiology 2009; 19: 479-87.

[39] Orntoft TF, Vestergaard EM, Holmes E, et al. Influence of Lewis alpha1-3/4-L-fucosyltransferase (FUT3) gene mutations on enzyme activity, erythrocyte phenotyping, and circulating tumor marker sialyl-Lewis a levels. J Biol Chem 1996; 271: 32260-8.

[40] Naarding MA, Ludwig IS, Groot F, et al. Lewis X component in human milk binds DC-SIGN and inhibits HIV-1 transfer to CD4+ T lymphocytes. J Clin Invest 2005; 115: 3256-64.

[41] Gambaryan AS, Tuzikov AB, Pazynina GV, et al. 6-sulfo sialy Lewis $\mathrm{X}$ is the common receptor determinant recognized by $\mathrm{H} 5$, $\mathrm{H} 6, \mathrm{H} 7$ and $\mathrm{H} 9$ influenza viruses of terrestrial poultry. Virol J 2008; 5: 85.

[42] Asakuma S, Akahori M, Kimura K, et al. Sialyl oligosaccharides of human colostrum: changes in concentration during the first three days of lactation. Biosci Biotechnol Biochem 2007; 71: 1447-51.

[43] Heinig MJ, Dewey KG. Health advantages of breast feeding for infants: a critical review. Nutr Res Rev 1996; 9: 89-110.

[44] Wang B. Sialic acid is an essential nutrient for brain development and cognition. Annu Rev Nutr 2009; 29: 177-222.

[45] Takeda T, Sakata M, Minekawa R, et al. Human milk induces fetal small intestinal cell proliferation-involvement of a different tyrosine kinase signaling pathway from epidermal growth factor receptor. J Endocrinol 2004; 181: 449-57.

[46] Kuntz1 S, Rudloff S, Kunz C. Oligosaccharides from human milk influence growth-related characteristics of intestinally transformed and non-transformed intestinal cells. Br J Nutr 2008; 99: 462-71.

[47] Elbim C, Hakim J, Gougerot-Pocidalo MA. Heterogeneity in Lewis- $\mathrm{X}$ and sialyl-Lewis-X antigen expression on monocytes in whole blood: relation to stimulus-induced oxidative burst. Am J Pathol 1998; 152: 1081-90.

[48] Bode L, Rudloff S, Kunz C, Strobel S, Klein N. Human milk oligosaccharides reduce platelet-neutrophil complex formation leading to a decrease in neutrophil beta 2 integrin expression. J Leukoc Biol 2004; 76: 820-6.

[49] Bode L, Kunz C, Muhly-Reinholz M, Mayer K, Seeger W, Rudloff $\mathrm{S}$. Inhibition of monocyte, lymphocyte, and neutrophil adhesion to endothelial cells by human milk oligosaccharides. Thromb Haemost 2004; 92: 1402-10.

[50] Liu FT. Regulatory roles of galectins in the immune response. Int Arch Allergy Immunol 2005; 136: 385-400.

[51] Ideo H, Seko A, Ohkura T, Matta KL, Yamashita K. High-affinity binding of recombinant human galectin-4 to $\mathrm{SO}_{3}$ $\rightarrow 3 \mathrm{Gal} \beta 1 \rightarrow 3 \mathrm{GalNAc}$ pyranoside. Glycobiology 2002; 12: 199208.

[52] Crocker PR, Paulson JC, Varki A. Siglecs and their roles in the immune system. Nat Rev Immunol 2007; 7: 255-66.

[53] Hara K, Ikeda M, Saito S, et al. Lactoferrin inhibits hepatitis B virus infection in cultured human hepatocytes. Hepatol Res 2002; 24:228-35

[54] Harmsen MC, Swart PJ, de Béthune MP, et al. Antiviral effects of plasma and milk proteins: lactoferrin shows a potent activity against both human immunodeficiency virus and human cytomegalovirus replication in vitro. J Infect Dis 1995; 172: 380-8. 
[55] Yolken RH, Peterson JA, Vonderfecht SL, Fouts ET, Midthun K, Newburg DS. Human milk mucin inhibits rotavirus replication and prevents experimental gastroenteritis. J Clin Invest 1992; 90: 198491.

Received: September 28, 2011

Revised: March 19, 2012

Accepted: March 28, 2012

(C) Yang et al.; Licensee Bentham Open.

This is an open access article licensed under the terms of the Creative Commons Attribution Non-Commercial License (http://creativecommons.org/licenses/by-nc/3.0/) which permits unrestricted, non-commercial use, distribution and reproduction in any medium, provided the work is properly cited. 